\title{
A Study on Contemporary Value of Marriage Law and Culture in the Western Zhou Dynasty
}

\author{
Yunpeng Gao \\ School of Political Science and Law, University of Jinan, Ji'nan, Shandong, 250022, China
}

\begin{abstract}
Key words: Marriage law and culture, Western Zhou Dynasty, Principle, Procedure of marriage establishment, Conditions, Contemporary value.
\end{abstract}

\begin{abstract}
In Chinese dynasties, only the legislative system of marriage and family in the Western Zhou Dynasty was most perfect. The conditions and principles for marriage establishment, marriage relation, and the conditions for termination of marriage in the system greatly influenced the development of Chinese marriage law since then, of certain law and culture reference significance and high theoretical and practical value. This paper aims to discuss the contents of the marriage law in the Western Zhou Dynasty and the constraints thereof, and analyze the value and significance of the marriage law in the Western Zhou Dynasty to contemporary marriage law and culture.
\end{abstract}

\section{Introduction}

The Western Zhou Dynasty was the heyday in the early "three dynasties" in Chinese history. Depending on the cultural accumulation in the Xia and Shang dynasties, the Western Zhou Dynasty had profound historical culture deposits and rich material base, which were reflected in every aspect of state construction in the Western Zhou Dynasty. Take the example of marriage system. As the most basic content in the civil law and rules, the marriage law system in the Western Zhou Dynasty was well-established and precise, which fully inherited the political thought of "the virtuous inheriting the mandate of heaven, and emphasizing virtue and being cautious with penalty" of state in this period. This suggests that since the Western Zhou Dynasty, rulers started to show a low-profile, and turned to placating the masses with virtue, with a hope to promote the development of civil law of the state with a gentle courtesy gesture. Especially in respect of the development of marriage system, "courtesy" became the key point of constraints of state laws and conventional morality, which gradually humanized and standardized the conditions for the establishment and termination of marriage and the procedures thereof.

\section{Contents of State Regulations on Marriage Management in the Western Zhou Dynasty}

In the Xia and Shang dynasties, the civil behaviors of the middle-and-bottom class, in particular of slaves, were designated by slave owner, and any slave individual had not decision-making power. Since the Western Zhou Dynasty, the bottom class obtained some freedom and rights. Especially, slave owners could not intervene in their right of marriage choice, which germinated and developed Chinese law and culture. In the Western Zhou Dynasty, when the establishment of marriage law system was attempted first, the marriage law was directly under the management of the state, and a marriage bureau was specially set up, and marriage officers were designated to fulfill the function of matchmaking. Regarding the construction of law contents, marriage officers' management over people's marriage began from the birth of child until the termination of the marriage contract. At that time, any newly-born child should be registered with the marriage bureau within three months since the birth, and deregistered before the child getting married. This procedure defined the intention of 
management of the government body over individual marriage in the Western Zhou Dynasty, of which the degree of standardization was unprecedented. From the aspect of humanization, the marriage bureau stipulated the age for marriage (male: 30, female: 20), and the marriage bureau would actively organized marriage officers to make a match for those reaching the specified ages. Besides, the marriage bureau would hold a matchmaking event in the second month of spring every year, to facilitate young men and women getting married. All these were recorded in the Book of Rites on Order, showing the state's meticulous management over people's marriage in the Western Zhou Dynasty.

\section{Procedure of Marriage Establishment in the Western Zhou Dynasty and Cultural Interpretation thereof}

The marriage law system in the Western Zhou Dynasty was considerably sound, which meticulously specified the principle and procedure of marriage establishment. This formed a delightful contrast with the connotation of social and cultural tradition in the Western Zhou Dynasty, and reflected the decision of rulers of the Western Zhou Dynasty to develop the marriage law, stabilize the people and prosper the state.

\section{Basic Principle for Marriage Establishment in the Western Zhou Dynasty}

In the Western Zhou Dynasty, stress was laid on patriarchal clan system, which was the basic social formation at that time. From the perspective of marriage law system, people were stipulated to observe the monogamy and the rule of no marriage within the same family name, which were the two core principles for marriage establishment in the Western Zhou Dynasty. In the Western Zhou Dynasty, due to legal status difference between man and woman, their family statuses in marriage also differed greatly. Thus, men were allowed to have concubines, but the children of the wife and of the concubines enjoyed totally different family statuses. In the viewpoints of people in the Western Zhou Dynasty, this marriage law system made for the centralized accumulation of wealth of family and even the state, and was good for the lasting political stability of the state. Besides, the rule of no marriage within the same family name was another distinctive rule in the Western Zhou Dynasty. People in the Western Zhou Dynasty tended to think marriage within the same family name would result in feeble and sick later generations and family disasters, and affect the thriving of population. Hence, marriage within the same family name was prohibited by law in the Western Zhou Dynasty. It is thus clear that the intention of strengthening force and consolidating social development and stability via marriage and blood blond is the basic reason for the thriving of the marriage law and culture of the Western Zhou Dynasty.

\section{Basic Procedure of Marriage Establishment in the Western Zhou Dynasty.}

"Words of matchmakers and dictates of parents" fully reflects the strict marriage system ancient China, and also shows the basic procedure of marriage establishment in the Western Zhou Dynasty. In the Western Zhou Dynasty, the conclusion of marriage contract was directly under the instructions of marriage officers, which was the only way that most men and women got married at that time. It reflects the real connotation of "a right and legal marriage" at that time.

The counterpart of words of matchmakers is the "dictates of parents", which was also an important prerequisite and procedure for marriage establishment. In short, dictates of parents mean that the establishment of marriage must be subject to the approval of parents of both sides. As a matter of fact, "dictates of parents" unveiled the political basis of state ruling in the Western Zhou Dynasty to a certain extent. What it showed was a kind of "co-construction of family and state" patriarchal clan system. To put it other way, it showed the political characteristics of ruling over countries with family's power. Obtaining words of matchmakers and approval by parents meant that half the procedure of marriage establishment had been finished. It can be said that the establishment of marriage based on the abovementioned procedure would not caused any social contradictions or 
family disputes. Hence, besides the Western Zhou Dynasty, other following dynasties also inherited this procedure of marriage establishment, which guaranteed the social stability and marital quality, and made marriage law and culture develop and continue.

\section{Other Expressions of the Marriage Law and Culture of the Western Zhou Dynasty}

"Six steps" and "ancestor worship" also were distinctive cultural expressions of the marriage law and culture of the Western Zhou Dynasty. On the wedding ceremony, the "six steps" must be gone through as a cultural form recognized by the legal system, namely "token of love, name-inquiry, propitious-sign-notification, betrothal gifts presentation, wedding date consultation, and bride fetching”. Token of love means the groom-to-be's family present a gift to the bride-to-be's family in token of love, which continues today and reflects the tyranny of the authority of the husband in ancient China; name-inquiry means the bride-to-be inquiries about the name of the bride-to-be, which reflects that the marriage view in the Western Zhou Dynasty was completely affected by the theory of heaven and destiny. Specifically, it was believed that marriage was made in heaven, and even every one had different destinies, marriage ties were made in heaven; if two persons insisted to get married despite that their destinies were told to restrain each other, then they would bring disasters to their families. Therefore, in the Western Zhou Dynasty, the establishment of any marriage must be subject to divination based on the names and family social standings of both sides. Based on the divination, the future would be predicted. This was propitious-sign-notification. The following step was betrothal gifts presentation, which means the groom-to-be took betrothal gifts to the home of the bride-to-be to conclude a marriage contract. The gifts in this link were much more valuable than that in token of love, because the relationship was formally established in this link, which led to marriage directly. After betrothal gifts presentation, wedding date consultation should be gone through. The task of wedding date consultation was to select a lucky day for wedding, which also was conducted together with betrothal gifts presentation. In this link, the parents of the bride-to-be would be consulted for the wedding date. After engagement, the last link was bride fetching, which was followed by wedding. The groom-to-be fetched the bride-to-be home to finish the wedding ceremony, and the marriage was established.

The wedding was followed by ancestor worship. In the Western Zhou Dynasty, bride fetching indicated that the groom-to-be had been qualified to be a husband only. If he wanted his marriage to be widely recognized, he must dress in attire after having a bath three months after the wedding, and carry out ancestor worship after asking for instructions from the parents of both sides, to obtain the acquiescence of ancestors. After ancestor worship, it could be formally declared that the bride had joined in, become a member of, and obtained certain status in the patriarchal clan of her husband.

The above is about the whole procedure of marriage establishment in the Western Zhou Dynasty, which blended in the political and legal basis of the state at that time and the folk customs and etiquette of the Western Zhou Dynasty having been kept as a tradition, and fully showed the era characteristics and inheritable value of the marriage law and culture of the Western Zhou Dynasty. ${ }^{[1]}$

\section{Contemporary Value of the Marriage Law and Culture of the Western Zhou Dynasty}

According to the marriage law and culture of the Western Zhou Dynasty and its cultural expressions, though the system was well established, it is subject to historic limitations. Some legal systems and cultures continue today, while others are denied. As a whole, the marriage law and culture of the Western Zhou Dynasty are of certain enlightenment and reference significance, because there are valuable ideas and cultural details existing in the system, which are still influencing the marriage custom today, and exert a mapping effect, as below.

\section{Legalization of Marriage and Family}

The Western Zhou Dynasty was the first dynasty when marriage and family were legalized in Chinese history, which stopped the situation where people's marriage relations were unordered, fixed 
marriage relations, consolidated the life order in human society at that time, and optimized the group combination of human being. In the Western Zhou Dynasty, people learned to explicitly confirm marriage relations by law, and verify the validity of marriage relations, which was the positive reflection of the family institution and patriarchal system. Comparing with that the freedom and liberty of slaves were decided by slave owners in the Xia and Shang dynasties, the intervention in marriage by means of law and state coercive power was more humanistic and normalized, which was also a model of shaping marriage form via social culture and political history. Particularly, the establishment of the monogamy had influenced the social, humanistic, and ethical development subsequently, which is of great reference significance to contemporary researches of social sciences and humanities.

\section{Enlightenment of the System of Freedom of Marriage on Modern Marriages}

According to the modern marriage law, marriage essentially is a question that can't be evaded in family institution, which relating to from the concept of marriage to the legal position of marriage and family. Different from individualism-based contracts, marriage is a presentation surpassing individualism, and reflects the essence of private freedom in marriage and the basic property of marriage contract. At present, marriage should fall into the scope of private law regulation. The nature of institutional development of contemporary community of marriage also can be seen from the construction of the marriage law system in the Western Zhou Dynasty, which even involves the common interests of society and state, and gradually tend to resort to public law for regulation and problem solving. With regard to the subject of marriage relation, the enlightenment of the marriage law and culture of the Western Zhou Dynasty on the freedom of marriage in modern times is that more attention should be paid to individuals' life and children's growth. From the angle of the development of social environment, it unveiled that human trafficking and arranged marriage should be forbidden in individual marriage, which should be criticized and stopped as bad traditional practices. It is thus clear that the openness of the marriage law and culture of the Western Zhou Dynasty is still worth deliberating and researching. If the principle of freedom of marriage can be fully implemented, a great influence will be brought to the whole society ${ }^{[2]}$.

\section{View of Marriage of Giving Priority to Ethics and Integration of Affection and Ethics}

There was a saying of "a wife should not be divorced in three conditions" in the Western Zhou Dynasty as stated in the Book of Rites-Natal Chart. If a man intended to divorce his wife when there was no person surviving in his wife's parents' home, the divorce should not be approved; if a married woman had observed mourning for her husband's parent together with her husband for three years, the woman should not be divorced; if a couple had had experienced hardships, the man should not divorced his wife when he became illustrious and influential. This showed that priority was given to ethics and affection and ethics were integrated in the marriage system in the Western Zhou Dynasty, which reflected that the traditional authority of the husband in ancient China strived to safeguard the patriarchal system, and the rulers strived to maintain ethics and morals. They were the two bases for the marriage law and culture of the Western Zhou Dynasty, and defended the dominant position of the rulers. From the perspective of women, the marriage system of the Western Zhou Dynasty protected the rights and interests of women, and defended the dominant position of the rulers. On this basis, it can be seen that the marriage law and culture of the Western Zhou Dynasty had perfectly balanced humanization and ethics, in which the patriarchal clan system and ethics and morals were taken as the ruling foundation, and the validity of the patriarchal clan system and the advancement and humanization of marriage morals and ethics were reflected in marriage management. It is worth learning.

\section{Modern Significance of Substantial Element System in the Marriage Law and Culture}

The marriage law system of the Western Zhou Dynasty explicitly specified the age of marriage based on physiological and ethic considerations. It should be noted that the age of marriage for the male 
greatly differed from that for the female in the Western Zhou Dynasty, which reflected the social and natural factors in the issue of the age of marriage, and certain social significance of marriage. Presently, the age of marriage in Chinese laws is also different from that of full capacity for civil conduct. Especially in the aspect of legal principle, the definition of the age of marriage involves comprehensive considerations of politics, economy and population. It is the definition of the age of marriage in the marriage law and cultures in the Western Zhou Dynasty that inspired lawmakers to define the age of the capacity for private rights and of the capacity for civil conduct, and profoundly affected the history of the Chinese nation and the process of human reproduction. The interpretation of the elements affecting the definition of the age of marriage in the Western Zhou Dynasty should not be stopped here, but more analyses from the perspective of patriarchal clan system and politics should be made, to deeply understand the practical value and significance of the marriage system at that time to the development of modern marriage law and cultures ${ }^{[3]}$.

\section{Summary}

The Western Zhou Dynasty is a typical period transiting from slave society to feudal society, and the uniqueness of marriage law system and system in this period was unprecedented. The patriarchal clan system of the Western Zhou Dynasty laid a solid foundation for the morality, amenity, and hierarchy in modern marriage in China, and plays an important role in preservation of some good Chinese traditions of which Chinese people are proud. Of course, the marriage law system of the Western Zhou Dynasty also was subject to limitations and had epochal character, which needs to be deeply explored and researched, and innovated and re-interpreted based on modern characteristics. On this basis, the modern marriage law can be further improved, and new attempt can be made to inherit the marriage culture.

\section{Acknowledgments}

This paper is a key project of 2016 Jinan Philosophy and social science program, of which the title is A Study on Contemporary Value of Marriage Law and Culture in the Western Zhou Dynasty JNSK16B21.

\section{References}

[1] Wu Huijuan. Research on Marriage Law System of the Western Zhou Dynasty. Lantai World,2013(3):12-13.

[2] Hou Jun. Brief Discussion on the Influence of Marriage Law System of the Western Zhou Dynasty on Later Generations. Science and Technology Innovation Herald, 2014(33):214-214.

[3] Tang Yiping, Liu Xinguo. Realistic Significance of the Marriage and Family System of the Western Zhou Dynasty. Journal of Hunan Radio \& TV University, 2002(4):40-43. 